\title{
Synthesis and characterization of cadmium doped lead-borate glasses
}

\author{
A A ALEMI*, H SEDGHI', A R MIRMOHSENI and V GOLSANAMLU \\ Department of Inorganic Chemistry, Faculty of Chemistry, University of Tabriz, Tabriz, Iran \\ ${ }^{\dagger}$ Department of Physics, Science Faculty, Urmia University, Iran
}

MS received 28 April 2005; revised 20 October 2005

\begin{abstract}
Cadmium doped lead-borate glasses were prepared from the melts in appropriate proportions of $\mathrm{PbO}_{2}, \mathrm{H}_{3} \mathrm{BO}_{3}$ and $(15-40 \mathrm{~mol} \%) \mathrm{CdO}$ mixture in the temperature range $700-950{ }^{\circ} \mathrm{C}$. The infrared spectra of the glasses in the range $400-4000 \mathrm{~cm}^{-1}$ show their structures. No boroxol ring formation was observed in the structure of these glasses. Furthermore, doped cadmium atoms were not seen in tetrahedral coordination. But the conversion of three-fold to four-fold coordination of boron atoms in the structure of glasses was observed.
\end{abstract}

Keywords. Cadmium; lead borate glasses.

\section{Introduction}

Infrared spectroscopy and Raman scattering are two important spectroscopic methods applied in the structural investigation of the local order characterizing vitreous materials like oxide glasses (Hassan et al 1992; Martino et al 2001; Yiannopoulos et al 2001). $\mathrm{B}_{2} \mathrm{O}_{3}$ is one of the most common glass formers and is present in almost all commercially important glasses. It is often used as a dielectric material and borate glasses possess scientific interest because of the occurrence of boron anomaly (Griscon 1978). Synthesis and study of lanthanum borate (Hinatsu et al 2003), aluminum borate whiskers (Alemi and Hinatsu) and borate glasses, in particular, have become subjects of great interest for infrared studies, due to their structural peculiarities (Kamitsos and Karakassides 1989; Motke et al 2002). In borate glasses, $\mathrm{B}_{2} \mathrm{O}_{3}$ is a basic glass former because of its higher bond strength, lower cation size and smaller heat of fusion, so the structural investigation of boron in these glasses is one of the most attractive points of borate glass formation and related doped systems. In borate glasses, $\mathrm{B}^{3+}$ ions are triangularly coordinated by oxygen atoms and the triangle units are corner bounded in a random configuration (Yawale et al 2000). $\mathrm{PbO}$ and $\mathrm{ZnO}$ can enter the glass network both as a network former and also as a network modifier and due to this the structure of this glass is expected to be different from that of alkali borate glasses. The structure of borate glasses is completely different from other glasses such as phosphate glasses and silicate glasses.

In the present paper, synthesis and characterization of lead borate glasses, doped with cadmium oxide are studied with the help of infrared and Raman spectroscopy to determine the

*Author for correspondence (alemi@tabrizu.ac.ir; aa_alemi@yahoo.com) structure of borate glasses containing varying amounts of $\mathrm{PbO}_{2}$ and $\mathrm{CdO}$.

\section{Experimental}

\subsection{Sample preparation}

Cadmium doped lead-borate glasses were prepared from analar grade powders of $\mathrm{H}_{3} \mathrm{BO}_{3}, \mathrm{PbO}_{2}$ and $\mathrm{CdO}$ which were thoroughly mixed in the composition range of $x \mathrm{PbO}_{2}$ $(50-x) \mathrm{CdO}-50 \mathrm{~B}_{2} \mathrm{O}_{3}$, where $x=10,15,20,25,30$ and $35 \mathrm{~mol} \%$. The appropriate amount of chemicals were mixed and heat treated in open porcelain crucible on a kerr 666 electric furnace. Initially, the samples were maintained for $1 \mathrm{~h}$ at the temperature range from $450-550^{\circ} \mathrm{C}$ for decomposition of boric acid. Then the temperature was raised up to $750-900^{\circ} \mathrm{C}$ and maintained for $2 \mathrm{~h}$ and the melt was poured between two stainless steel mould plates. Samples were quenched at $250^{\circ} \mathrm{C}$ in order to prevent crackings on the glasses and these glasses were yellow in colour.

\section{$2.2 X$-ray diffraction}

The glassy nature of the samples was confirmed by XRD studies using D5000 Siemens with $\mathrm{Cu}-\mathrm{K} \alpha$ line of wavelength $\lambda=1.5418 \AA$ at the scanning rate of $2 / \mathrm{min}$ and $2 \theta$ was varied from $4-70^{\circ}$.

\subsection{DSC thermogram}

The glassy nature of prepared glass $\left(30 \mathrm{PbO}_{2}-20 \mathrm{CdO}-\right.$ $50 \mathrm{~B}_{2} \mathrm{O}_{3}$ ) was confirmed by the differential thermal studies using Shimadzu DSC60 differential scanning calorimeter (DSC) in the temperature range from $30-500^{\circ} \mathrm{C}$ with a heating rate of $10^{\circ} \mathrm{C} / \mathrm{min}$ under nitrogen atmosphere. 


\subsection{Infrared spectra}

In the present work, the FTIR transmission spectra in the region $400-4000 \mathrm{~cm}^{-1}$ were recorded for all the samples using FT-IR Nexus 670 by $\mathrm{KBr}$ pellet technique.

\subsection{Density measurement}

The density of glass samples was measured using Archimedes's principle. The measurements were done using Shimadzu Aw 200 balance and xylene as an inert immersion liquid. The density was obtained from the relation

$$
d\left(\mathrm{~g} / \mathrm{cm}^{3}\right)=[a /(a-b)] x(\text { density of the xylene }),
$$

where $a$ is the weight of the glass sample in air and $b$ the weight of the glass sample when immersed in xylene. The density of xylene is $0.865\left(\mathrm{~g} / \mathrm{cm}^{3}\right)$ (Karthikeyan and Mohan 2003).

\subsection{Refractometer}

The refractive indices of the prepared glasses were measured on a microscope (ARL-ZEISS 4685266) and luxmeter.

\section{Results and discussion}

\section{$3.1 X$-ray diffraction}

The X-ray diffraction pattern of CdO-doped lead-borate glasses show no sharp peaks indicating amorphous nature.

\subsection{Thermal analysis}

The DSC thermogram of $30 \mathrm{PbO}_{2}-20 \mathrm{CdO}-50 \mathrm{~B}_{2} \mathrm{O}_{3}$ glass is shown in figure 1 . From this figure it is observed that the glass transition temperature of the sample is $370^{\circ} \mathrm{C}$.

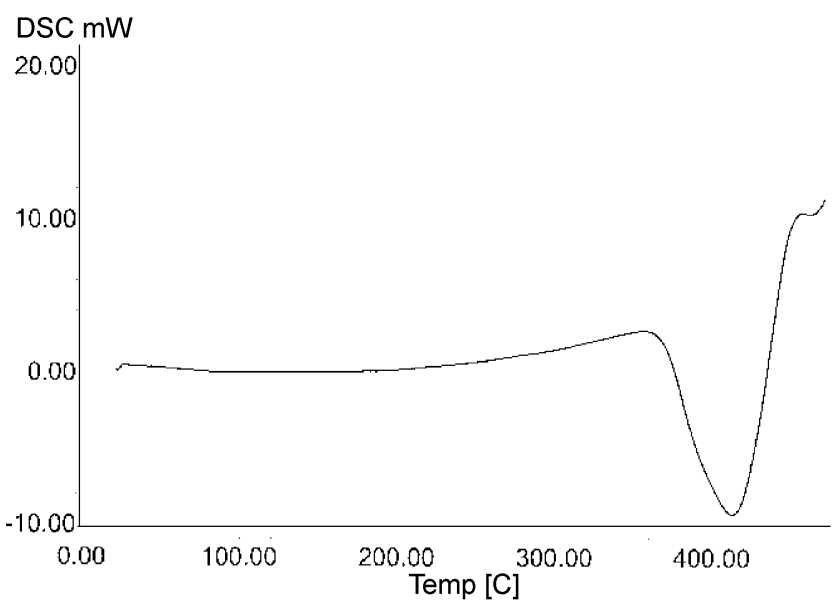

Figure 1. DSC thermogram of $30 \mathrm{PbO}_{2}-20 \mathrm{CdO}-50 \mathrm{~B}_{2} \mathrm{O}_{3}$ glass.

\subsection{FTIR and Raman analysis}

The FTIR spectra of doped glasses were obtained using $\mathrm{KBr}$ pellet technique in the range $400-4000 \mathrm{~cm}^{-1}$. The broad composite bands extending from $3200-3600 \mathrm{~cm}^{-1}$ are attributed to hydroxyl or water groups (Adams and Douglas 1959; Scholzelt 1991). In figure 2, it can be seen that there is no effect of composition on the types of the structural groupings. This may be due to presence of symmetric $\left(\mathrm{BO}_{3}\right)^{3-}$ triangles, $\left(\mathrm{BO}_{4}\right)^{4-}$ tetrahedral and asymmetric $\left(\mathrm{BO}_{3}\right)^{3-}$ units (non-bridging oxygen) in each of the samples of $\mathrm{PbO}_{2}-\mathrm{CdO}-\mathrm{B}_{2} \mathrm{O}_{3}$ glasses. Furthermore, it is noticed that in the spectra containing different concentrations of $\mathrm{CdO}$, the structure is not changed.

According to the Krogh Moe's model, the structure of boron oxide glass consists of a random network of planar $\mathrm{BO}_{3}$ triangles with a certain fraction of six membered (boroxol) rings (Moe 1965). X-ray diffraction data suggest that glass structure consists of a random network of $\mathrm{BO}_{3}$ triangles without boroxol rings. The vibrational modes of the borate network are seen to be mainly active in three infrared spectral regions, which are similar to those reported by several workers (Kamitsos et al 1987; Ghoneun et al 1996): (i) the first group of bands which occur at 1200$1600 \mathrm{~cm}^{-1}$ is due to the asymmetric stretching relaxation of the $\mathrm{B}-\mathrm{O}$ band of trigonal $\mathrm{BO}_{3}$ units, (ii) the second group lies between 800 and $1200 \mathrm{~cm}^{-1}$ and is due to the $\mathrm{B}-\mathrm{O}$ bond stretching of the tetrahedral $\mathrm{BO}_{4}$ units and (iii) the third group is observed around $700 \mathrm{~cm}^{-1}$ and is due to bending of B-O-B linkages in the borate networks. The infrared spectra of these glasses show seven to eight absorption peaks. The peaks are sharp, medium, weak and broad. The broad bands are exhibited in the oxide spectra, probably due to the combination of high degeneracy of vibrational states, thermal broadening of the lattice dispersion band and mechanical scattering from powder samples. In the present glass, the absence of absorption peak at $806 \mathrm{~cm}^{-1}$ indicates the absence of boroxol ring formation. The progressive substitution of boroxol rings by triborate and tetraborate groups is observed. In pure $\mathrm{B}_{2} \mathrm{O}_{3}$ glass, the $806 \mathrm{~cm}^{-1}$ frequency is a characteristic of boroxol ring. The vanishing of $806 \mathrm{~cm}^{-1}$ means no boroxol ring in the glass structure; ultimately it consists of $\mathrm{BO}_{3}$ and $\mathrm{BO}_{4}$ groups. These groups may be attached in the form of random network. This corresponds to the progressive substitution of boroxol ring by $\mathrm{BO}_{3}$ and $\mathrm{BO}_{4}$ groups. This type of behaviour is observed in $\mathrm{B}_{2} \mathrm{O}_{3}-\mathrm{Li}_{2} \mathrm{O}$ glasses (Galeener et al 1980; Kulkarni et al 1984; Kanehisa and Elliot 1989). The absorption band at $1307 \mathrm{~cm}^{-1}$ is associated with $\mathrm{B}(\mathrm{III})-\mathrm{O}-\mathrm{B}(\mathrm{IV})$ stretching vibrations. The band around $1357 \mathrm{~cm}^{-1}$ is assigned to $\mathrm{B}-\mathrm{O}$ stretching vibrations of trigonal $\left(\mathrm{BO}_{3}\right)^{3-}$ units in metaborates, pyroborates and orthoborates (Chekhovskii 1985). On passing from boron trioxide to borate glasses in the coordination number, boron takes place. In these glasses, the boron is tetrahedrally surrounded by four oxygen atoms (Biscoe and Warren 1938). The band around $1292 \mathrm{~cm}^{-1}$ is due to $\mathrm{B}-\mathrm{O}$ 


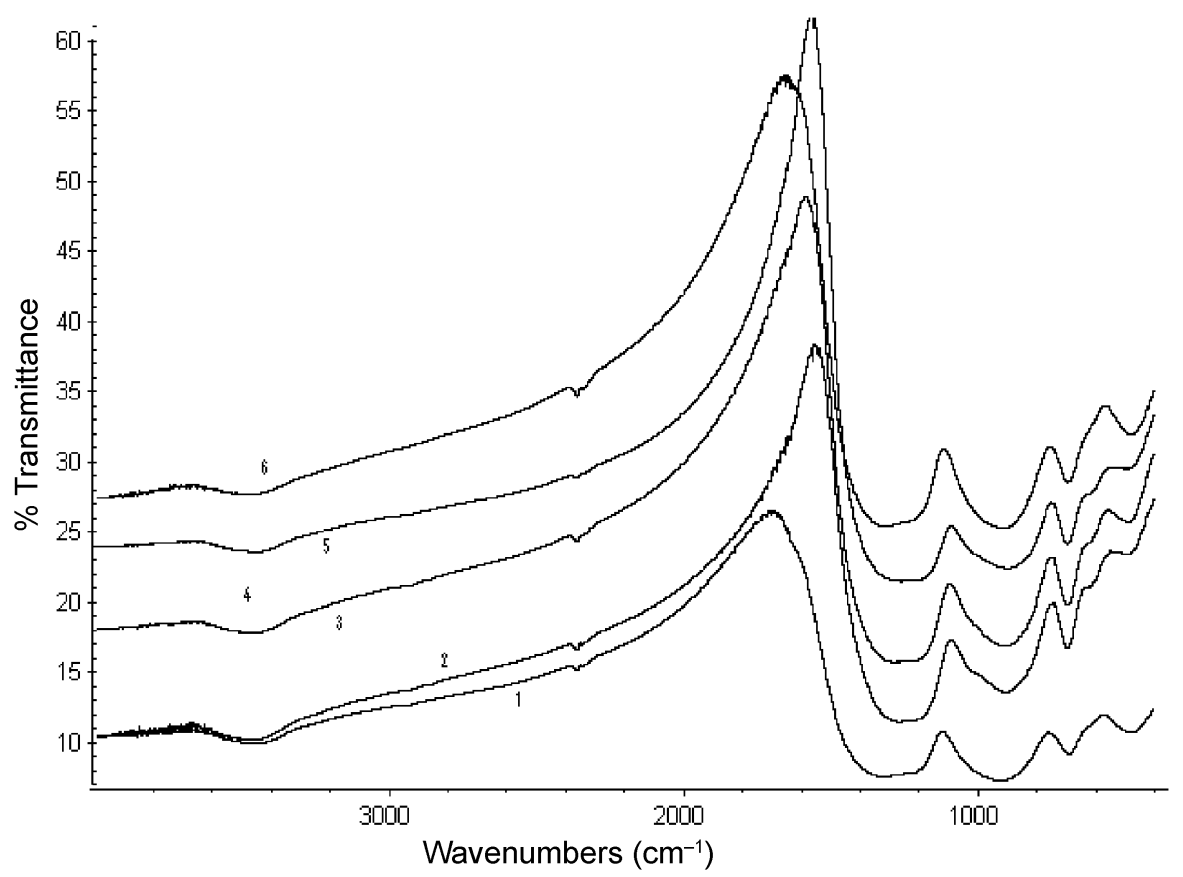

Figure 2. FTIR spectra of $x \mathrm{PbO}_{2}-(50-x) \mathrm{CdO}-50 \mathrm{~B}_{2} \mathrm{O}_{3}(1: x=10,2: x=15,3: x=20,4$ : $x=25,5: x=30,6: x=35$ ).

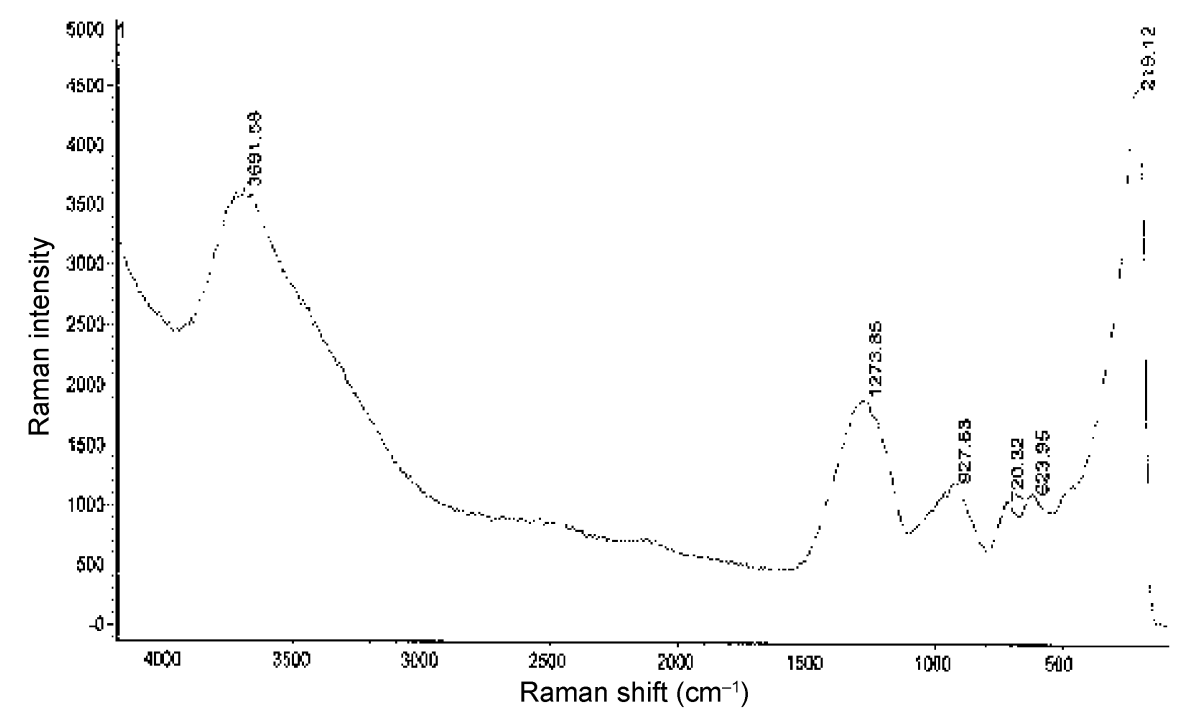

Figure 3. Raman spectrum of $30 \mathrm{PbO}_{2}-20 \mathrm{CdO}-50 \mathrm{~B}_{2} \mathrm{O}_{3}$ glass.

Table 1. Physical properties of cadmium doped lead-borate glass.

\begin{tabular}{llc}
\hline No. & Physical properties & \\
\hline 1 & Density $\left(\mathrm{g} / \mathrm{cm}^{3}\right)$ & $5 \cdot 81$ \\
2 & Dielectric constant & $3 \cdot 71$ \\
3 & Reflection loss $(R \%)$ & 10 \\
4 & Refractive index & $1 \cdot 925$ \\
\hline
\end{tabular}

asymmetric stretching of $\mathrm{BO}_{3}$ unit (Heaton and Moore 1987). The shoulder at $1234 \mathrm{~cm}^{-1}$ may arise from $\mathrm{B}-\mathrm{O}$ stretching vibrations of $\left(\mathrm{BO}_{3}\right)^{3-}$ unit in metaborate chains and orthoborates (Kamitsos et al 1990). Similarly the band at $1005 \mathrm{~cm}^{-1}$ is due to vibration of some atoms attached to nonbridging oxygen in the form of $\mathrm{BO}_{4}$ vibration (Ito and Miyauchi 1983). The absorption around $1000 \mathrm{~cm}^{-1}$ indicates formation of diborate groups in the present glasses. The shoulder at $1021 \mathrm{~cm}^{-1}$ is due to stretching vibrations of tetrahedral $\mathrm{BO}_{4}$. In IR spectra of $\mathrm{Na}_{2} \mathrm{O}-\mathrm{B}_{2} \mathrm{O}_{3}-\mathrm{SiO}_{2}$ glasses the band at about $995 \mathrm{~cm}^{-1}$ is attributed to a stretching vibration of $\mathrm{B}-\mathrm{O}-\mathrm{Si}$ linkage. Similarly the presence of the band at $992 \mathrm{~cm}^{-1}$ in the spectra may be assigned to a stretching vibration of $\mathrm{B}-\mathrm{O}-\mathrm{M}(\mathrm{B}-\mathrm{O}-\mathrm{Pb})$ linkage where $\mathrm{M}$ represents a metal ion. The absorption band at $696 \mathrm{~cm}^{-1}$ 
is due to combined vibration of $\mathrm{BO}_{4}$ and $\mathrm{PbO}_{4}$ groups. The band around $699 \mathrm{~cm}^{-1}$ indicates that oxygen bridges two trigonal boron atoms. In $50 \mathrm{~Pb}_{2}-50 \mathrm{~B}_{2} \mathrm{O}_{3}$ glass system the absorption band at 828 and $1130 \mathrm{~cm}^{-1}$ was reported by Doweidar et al (1991). In present $\mathrm{PbO}_{2}-\mathrm{CdO}-\mathrm{B}_{2} \mathrm{O}_{3}$ glasses, it is found that the bands are absent. Probably this may be due to substitution of $\mathrm{CdO}$ for fraction of $\mathrm{PbO}_{2}$ contents. The absorption at region $840 \mathrm{~cm}^{-1}$ is not observed in these glasses, which suggests that the formation of tetrahedral coordination of $\mathrm{Cd}$ (i.e. $\mathrm{CdO}_{4}$ ) is absent (Yawale et al 1995). Figure 3 indicates the Raman spectrum of $30 \mathrm{PbO}_{2}-$ $20 \mathrm{CdO}-50 \mathrm{~B}_{2} \mathrm{O}_{3}$ glass which has a strong absorption band in the region $200-300 \mathrm{~cm}^{-1}$ which corresponds to $\mathrm{Cd}-\mathrm{O}$ vibrational modes (Robinson 1991). The other absorption bands have been discussed in its FTIR spectra.

\subsection{Refractive index}

Refractive index has been measured using a Luxmeter. The transition coefficient $\left(T_{n}\right)$ and its relations with Furnel coefficient was also used to calculate the amount of refractive index. The physical properties of cadmium doped lead borate glass is shown in table 1 .

Transition coefficient,

$$
\begin{aligned}
& T_{n}=\frac{\text { Intensity of transmitted light }}{\text { Intensity of incident light }} \quad T_{n}=0 \cdot 9, \\
& T_{n}=\frac{n_{2}}{n_{1}} t_{12}^{2}, \text { Furnel transition coefficient, } t_{12}^{2}=\frac{2 n_{1}}{n_{1}+n_{2}}, \\
& T_{n}=\frac{n_{2}}{n_{1}}\left[\frac{2 n_{1}}{n_{1}+n_{2}}\right]^{2}=\frac{n_{2}}{1}\left[\frac{2}{1+n_{2}}\right]^{2},
\end{aligned}
$$

the refractive index of the air, $n_{1}=1$,

$$
0 \cdot 9=\frac{n_{2}}{1}\left[\frac{2}{1+n_{2}}\right]^{2} \Rightarrow n_{2}=1 \cdot 925
$$

The measured refractive index has been 1.92 for the glasses by using direct optometry with a microscope and agreed well in both the approaches.

\section{Conclusions}

We conclude that the structure of cadmium doped lead borate glasses consists of $\mathrm{BO}_{3}$ and $\mathrm{BO}_{4}$ groups which are connected randomly. The structures of present glasses are independent of their compositions. The small changes occurring in the absorption bands do not account for major structural changes.

\section{Acknowledgements}

With thanks, the authors acknowledge the financial support from the Council of Tabriz University and the "Management and Planning Organization" of Islamic Republic of Iran.

\section{References}

Adams R V and Douglas R W 1959 J. Soc. Glass Technol. 43147

Alemi A A and Hinatsu Y Unpublished work

Biscoe J and Warren B E 1938 J. Am. Ceram. Soc. 21287

Chekhovskii V G 1985 Ffisika I Khimiya Stekla 1124 (English Translation)

Doweidar H, Abouzeid M A and El-Damrawi G M $1991 \mathrm{~J}$. Phys. D: Appl. Phys. 242222

Galeener F L, Lucovsky G and Mikkelsen J C 1980 Phys. Rev. B22 3983

Ghoneun N A, El Batul H A, Abdel Shafi N and Azooz M H 1996 Proceeding of Egyptian conference of chemistry (Egypt) p. 162

Griscon D L 1978 Borate glasses: Materials science research (New York: Plenum) Ch. 12, p.36

Hassan A K, Torell L M, Borjesson L and Doweidar H 1992 Phys. Rev. B45 12797

Heaton H M and Moore H 1987 J. Phys. Chem. Glasses 28 203

Hinatsu Y, Doi Y, Ito K, Wakeshima M and Alemi A A $2003 \mathrm{~J}$. Solid State Chem. 172438

Ito Y and Miyauchi K 1983 J. Non-Cryst. Solids 57389

Kamitsos E I and Karakassides M A 1989 J. Phys. Chem. Glasses 3019

Kamitsos E I, Karakassides M A and Chryssikos G D 1987 Phys. Chem. Glasses 911073

Kamitsos E I, Patsis A P, Karakassides M A and Chryssikos G D 1990 J. Non-Cryst. Solids 12652

Kanehisa M A and Elliot R J 1989 Mater. Sci. Engg. B3 163

Karthikeyan B and Mohan S 2003 Physica B334 298

Kulkarni A R, Maiti H S and Paul A 1984 Bull. Mater. Sci. 6 207

Martino D Di, Santos L F, Marques A C and Almeida R M 2001 J. Non-Cryst. Solids 293394

Moe U K 1965 Phys. Chem. Glasses 646

Motke S G, Yawale S P and Yawale S S 2002 Bull. Mater. Sci. 2575

Robinson J W 1991 Practical handbook of spectroscopy (ed.) J W Robinson (USA: CRC Press Inc.) 1st ed., Ch. 5, p. 533

Scholzelt H 1991 Glass: nature, structure and properties (New York: Springer Verlag)

Yawale S P, Pakade S V and Adgaonkar C S 1995 Indian J. Pure \& Appl. Phys. 3335

Yawale S S, Yawale S P and Adgaonkar C S 2000 Indian J. Eng. Mater. Sci. 7150

Yiannopoulos Y D, Chryssikos G D and Kamitsos E I 2001 Phys. Chem. Glasses 42164 